УДК 616-089.844-001.45-,617.58

DOI: $10.26435 /$ UC.V0I1(30).290

\author{
А.А. Оприщенко ${ }^{1}$, А.А. Штутин ${ }^{1}$, И.В. Коктышев ${ }^{2}$ \\ 1Республиканский травматологический центр, Донецк \\ ${ }^{2} Г 00$ ВПО «Донецкий национальный медицинский университет имени М. Горького», Донецк
}

\title{
ТАКТИКА ПЛАСТИЧЕСКОГО ЗАКРЫТИЯ ОГНЕСТРЕЛЬНЫХ РАНЕВЫХ ДЕФЕКТОВ НИЖНЕЙ КОНЕЧНОСТИ
}

Огнестрельные ранения конечностей, преимущественно нижних, составляют около 70\% в структуре боевых повреждений $[1,2]$. В условиях военных конфликтов последних десятилетий боевые повреждения возникают преимущественно вследствие применения взрывных устройств и боеприпасов, характеризующихся значительным разрушающим воздействием [1-5].Значительная часть из них сопровождается наличием первичного или формированием вторичного дефекта кожных покровов и подлежащих тканей, что во многом определяет характер течения раневого процесса, риск развития осложнений, продолжительность лечения и анатомофункциональный исход [6-9]. Первичное закрытие огнестрельных раневых дефектов не представляется возможным вследствие особенностей огнестрельного повреждения, тяжести общего состояния раненых, медико-тактических обстоятельств [7-9]. В связи с этим пластическое закрытие боевых раневых дефектов выполняется в отсроченном порядке. Несмотря на значительный опыт по закрытию огнестрельных дефектов конечностей продолжаются дискуссии о преимуществах, недостатках и целесообразности использования различных хирургических технологий, в том числе пластики осевыми кровоснабжаемыми лоскутами [7-9]. В условиях локальных военных конфликтов при ограниченных материально-технических возможностях выполнения реконструктивно-пластических вмешательств данный вопрос приобретает особое значение. В этой связи проблема определения рациональных подходов к выбору метода пластики огнестрельных раневых дефектов сохраняет актуальность.

\section{ЦЕЛЬ ИССЛЕДОВАНИЯ}

Анализ эффективности различных вариантов пластического закрытия огнестрельных дефектов нижних конечностей в условиях локального военного конфликта.

\section{МАТЕРИАЛ И МЕТОДЫ}

Проведен ретроспективный анализ 119 клинических наблюдений раненых с открытыми боевыми повреждениями нижних конечностей, сопровождающихся глубокими и обширными дефектами мягких тканей. Мужчин было 106 (89,1\%), женщин - 13 (10,9\%). Средний возраст 34,3 $\pm 2,9$ года (от 21 до 51). Пулевые ранения имели место у 28 (23,5\%), взрывная травма - 91 (76,5\%), в том числе минно-взрывные повреждения - 43 (36,1\%) раненых. Переломы IIIB типа (по классификации Gustilo-Andersen) [10] имели место у 76 (63,9\%) раненых, разрушения конечности, повлекшие первичную ампутацию - 43 (36,1\%). Травматический шок 2-3 степени установлен у 27 (22,7\%) раненых. Первичная оценка тяжести повреждения конечностей проводилась по шкале MESS. Средний показатель составил 6,3×0,4 (от 3,0 до 8,0) баллов. Площадь раневых дефектов составила в среднем $107,1 \pm 12,0$ см$^{2}(79,5-186,5)$. Все раненые в экстренном порядке были оперированы в сроки до 6 часов от момента поступления в клинику. Производилась первичная хирургическая обработка ран (при разрушении сегментов конечности - первичная ампутация), при наличии перелома - стабилизация поврежденных сегментов аппаратами внешней фиксации стержневого или спице-стержневого типа. Раны оставляли открытыми под повязками с мазями на гидрофильной основе.

В послеоперационном периоде проводили комплексную медикаментозную терапию, направленную на предотвращение инфекционных осложнений и предупреждение прогрессирования зоны вторичного некроза тканей. Системная антибиотикопрофилактика проводилась цефалоспоринами 2 поколения в комбинации с сульбактамом и метронидазолом. Вазоак-

(c) А.А. Оприщенко, А.А. Штутин, И.В. Коктышев, 2019 (c) Университетская Клиника, 2019 
тивная терапия включала применение инфузионных средств в комбинации со спазмолитиками, дезаггрегантами, антигопоксантами и противоотечными препаратами. Так же назначали нейротропную и иммуномодулирующую терапию.

Тактика последующего лечения раненых с огнестрельными дефектами нижних конечностей определялась на основании комплексной оценки общей тяжести повреждения, тяжести состояния раненого и местного раневого статуса с использованием соответствующих шкал оценки ВПХ [11]. Принимались во внимание клинические данные и параметры гемограммы, данные биохимических и иммунологических анализов. Тем не менее, решающими в выборе метода кожно-пластического закрытия раневого дефекта считали его клиническую оценку на основе классификации АО [12].

В соответствии с избранной тактикой раненые были разделены на три группы: 1 группа 32 пациента с ранениями без обнажения кости и других важных анатомических образований (сосудисто-нервных пучков, крупных сухожилий, суставов), у которых использовали традиционные методы кожно-пластического закрытия ран; 2 группа - 56 раненых, которым применяли вакуумную терапию с последующей аутодермопластикой расщепленными или местными перемещенными лоскутами; 3 группа 31 раненый, которым закрытие ран производили посредством комбинированной васкуляризированной (островковой) лоскутной пластики. Группы были сопоставимы по демографическим параметрам, срокам доставки в клинику и объему догоспитальной помощи. Оценивали продолжительность стационарного лечения и ближайшие результаты.

Полученные данные представлены в формате частоты (\%) и среднее \pm ошибка репрезентативности $(\mathrm{M} \pm \mathrm{m})$.

Во всех случаях было получено информированное согласие на проведение исследований, использование материалов лечения и иссле- дований в научно-исследовательской работе и профессиональных публикациях. Данное исследование является фрагментом плановой НИР и одобрено местной комиссией по биоэтической экспертизе.

\section{РЕЗУЛЬТАТЫ И ОБСУЖДЕНИЕ}

Решение о варианте закрытия раневого дефекта принималось в течение первых 3-7 суток от момента ранения на основании динамической комплексной клинико-лабораторноинструментальной оценки. Распределение раненых по степени тяжести первичного повреждения кожных покровов представлено в таблице 1.

Анализ данных таблицы 1 показывает, что в структуре исследованной группы раненых преобладали тяжелые повреждения кожного покрова - повреждения 3 степени составили 56\%, 4-й - 29\%. Малое число раненых с наиболее тяжелой утратой кожного покрова (5 степень) на наш взгляд обусловлено тем, что большинство таких раненых подвергались первичной ампутации. Следует отметить, что 75\% раненых с относительно не тяжелыми повреждениями кожи 2-й степени лечились традиционными методами. Большинство раненых с повреждением кожных покровов 3-й степени получали лечение с использованием вакуумной терапии и традиционных способов кожно-пластических вмешательств. Вместе с тем, 60\% раненых с наиболее тяжелым дефектом кожи нуждались в применении сложных видов комбинированной пластики лоскутами с осевым типом кровоснабжения.

Локальная клиническая оценка раневого дефекта определяется не только степенью тяжести повреждения кожи, но и сухожильно-мышечных структур (табл. 2.).

Анализ данных таблицы 2 показывает, что степень тяжести повреждения мышечных и сухожильных образований существенно отличается от показателей степени тяжести повреждения кожных покровов, что вполне объяснимо с точки зрения механогенеза огнестрельной

Распределение раненых по степени первичного поражения кожных покровов

Таблица 1. по классификации АО (n / \%)

\begin{tabular}{cccccc}
\hline \multirow{2}{*}{ Группа } & \multicolumn{4}{c}{ Вид повреждения } & \multirow{2}{*}{ Всего } \\
\cline { 2 - 4 } & IO2 & IO3 & IO4 & IO5 & 32 \\
\hline \hline 1 группа & $9 / 28,1$ & $20 / 62,5$ & $3 / 9,4$ & - & 56 \\
\hline 2 группа & $3 / 5,4$ & $40 / 71,4$ & $10 / 17,9$ & $3 / 5,4$ & 31 \\
\hline 3 группа & - & $7 / 22,6$ & $22 / 71,0$ & $2 / 6,5$ & 119 \\
\hline ВСЕГО & $12 / 10,1$ & $67 / 56,3$ & $35 / 29,4$ & $5 / 4,2$ & 3 \\
\hline
\end{tabular}


Таблица 2.

Распределение раненых по степени повреждения сухожильно-мышечных структур по классификации АО (n / \%)

\begin{tabular}{ccccccc}
\hline \multirow{2}{*}{ Группа } & \multicolumn{5}{c}{ Вид повреждения } & \multirow{2}{*}{ Всего } \\
\cline { 2 - 6 } & МТ1 & МT2 & МT3 & МT4 & МТ5 & 32 \\
\hline \hline 1 группа & $13 / 40,6$ & $17 / 53,1$ & $2 / 6,3$ & - & - & 56 \\
\hline 2 группа & - & $9 / 16,1$ & $12 / 21,4$ & $19 / 33,9$ & $16 / 28,6$ & 31 \\
\hline 3 группа & - & - & $8 / 25,8$ & $15 / 48,4$ & $8 / 25,8$ & 119 \\
\hline Всего & $13 / 10,9$ & $26 / 21,8$ & $22 / 18,5$ & $34 / 28,6$ & $24 / 20,2$ & \\
\hline
\end{tabular}

травмы. Так, если повреждения кожи 4-5-й степени встречались в 33\% наблюдений, то аналогичные по степени повреждения мышц и сухожилий составили 49\%, что отвечает современным представлениям о механизме повреждающего воздействия огнестрельного оружия. Обращает на себя внимание и то, что повреждения кожи 3-й степени встретились в 56\% наблюдений, в то время как аналогичная степень повреждения мышечных структур зарегистрирована только у $18 \%$ раненых. Вместе с тем следует обратить внимание на то, что относительно небольшие кожные повреждения имели место у $11 \%$ раненых, у которых отсутствовали и повреждения глубоких структур - в этих случаях речь шла о касательных, рикошетных ранениях, или ранениях опосредованными ранящими агентами, то есть, вероятно, относительно низко энергетичных травмах. При этом ограниченные в пределах одного мышечного футляра повреждения мышц и сухожилий наблюдались у $22 \%$ раненых. Суммируя представленные данные, можно прийти к заключению, что локальная оценка раневого статуса в большей мере зависит от повреждения субфасциальных структур, нежели от внешнего покрова. Закрытие дефекта кожи может быть произведено традиционными методами расщепленной, полнослойной или локальной перемещенной пластики, тогда как закрытие глубоких дефектов тканей требует более сложного и дифференцированного лечения. В данной работе мы не приводим анализ структуры повреждений периферических нервов и магистральных сосудов, поскольку они не оказывали принципиального влияния на выбор тактики раннего восстановительного лечения.

Показаниями к использованию традиционной тактики этапного лечения считали глубокие кожные дефекты, которые не сопровождаются обнажением кости и/или зоны перелома и других важных анатомических структур (крупных сухожилий, капсулы суставов, сосудистонервных пучков), мышц более чем в пределах одной группы. На нижней конечности это боль- шинство ран бедра и задней поверхности голени. Такие раны подлежали консервативному лечению повязками с гидрофильными мазями или современными перевязочными средствами до момента регресса локального отека с последующим закрытием расщепленными кожными трансплантатами в сроки от 7 до 15 суток (15 пациентов), острой дермотензией (10 пациентов), или местной кожной пластике перемещенными лоскутами без осевого кровоснабжения (7 пациентов). Средний срок закрытия этих ран составил $29,5 \pm 5,4$ суток $(18,4$ - 38,6). Местных раневых осложнений при этом мы не наблюдали. Частичный лизис свободных расщепленных аутодермотрансплантатов имел место в 7 случаях, в 3 из которых потребовались повторные вмешательства. Во всех случаях ближайший результат лечения был оценен как удовлетворительный. Средний срок пребывания на койке составил 38,5 $\pm 7,2$ суток.

Во 2-ю группу включались пациенты с глубокими дефектами мягких тканей с повреждениями/дефектами мышц в нескольких фасциальных футлярах, прогрессирующим мионекрозом, обильной раневой экссудацией и признаками компартмент-синдрома. У этой категории раненых применение традиционного метода лечения ран сопряжено с высоким риском развития как местных, так и общих инфекционных осложнений, вплоть до развития сепсиса. В данной группе раненых выполнялись повторные программируемые вторичные хирургические обработки ран с наложением вакуумных повязок.

Лечение ран методом отрицательного давления осуществляли с помощью устройств IMPACTM306, GOMCO 6003 (США). При наложении повязок использовалась стерильная гидрофильная полиуретановая губка с размером пор от 400 до 2000 микрометров, которую дополнительно обрабатывали антисептиком тиротрицином. Во время повторных оперативных вмешательств, проведения некрэктомий в имеющийся мягкотканный дефект вкладывали стериль- 
ный пористый материал по контуру и размерам раны. Повязки фиксировались при помощи прозрачного адгезивного покрытия в виде стерильной пленки TEGADERMFILM 3M или IOBAN 3M. C помощью внешнего контрольного устройства в системе вакуумной аппаратуры поддерживался диапазон значений отрицательного давления от 90 до 120 мм рт. ст. (12-16 кПа).

Среднее время между сменами вакуумповязок составило 3,0 $\pm 0,6$ суток. Среднее количество смен повязок для подготовки ран к закрытию составило 3,0ะ1,0. В это время отмечалось значительное снижение отека конечности, очищение раны от раневого детрита, выраженный рост грануляций в ране. Во всех случаях на 9-12 сутки после начала лечения отрицательным давлением раны были готовы к закрытию. Окончательное закрытие ран произведено аутодермопластическим методом в 43 наблюдениях, в 13 случаях - путем перемещения кожных лоскутов. Средний срок стационарного лечения

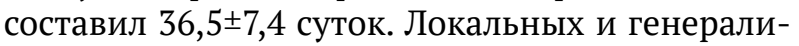
зованных инфекционных осложнений мы не наблюдали.

У раненых 3-й группы показаниями к применению пластики лоскутами с осевым типом кровоснабжения считали: обнажение костных фрагментов, в особенности в зоне перелома, обнажение суставов, крупных сухожилий и сосудистонервных пучков. При этом вакуумная терапия была использована в качестве предшествующего этапа в 5 наблюдениях для снижения объема раневой экссудации и подготовки реципиентной зоны. Лоскутную пластику выполняли на 7-28 сутки (в среднем 15 сутки) от момента ранения. Задний кожно-фасциальный лоскут бедра применили в 2 случаях для закрытия дефектов области коленного сустава. В 18 случаях использовали кожно-мышечный лоскут внутренней головки икроножной мышцы для укрытия коленного сустава и проксимальной средней трети голени (для средней трети голени - в комбинации с лоскутом камбаловидной мышцы). В 11 наблюдениях применили кожно-фасциальный суральный лоскут на дистальной ножке для закрытия дефектов в дистальной трети голени, области голеностопного сустава и стопы. Планирование лоскута во всех случаях осуществляли на основании тщательного допплерографического исследования, что считаем особенно важным при огнестрельной травме, когда дистанционные повреждения сосудистой системы конечности могут иметь решающее влияние на исход операции. При выполнении васкуляризированной пластики мы наблюдали частичный некроз 3 суральных лоскутов и 1 заднего лоскута бедра, которые потребовали местных кожно- пластических операций, однако не повлияли на конечный положительный исход лечения. Ретроспективно оценивая причины указанных осложнений, полагаем, что предварительная допплерографическая оценка не всегда позволяет в полной мере предоставить информацию о площади кровоснабжаемых перфорантными сосудами кожных территорий, а интраоперационные оценки носят субъективный характер. Факторами риска перфузионных нарушений являются так же преморбидный фон (все раненые были курильщиками) и уровень комплаентности пациента. Средний срок стационарного лечения раненых данной группы составил 46ะ9,8 суток $(39,5$ - 76,8). Инфекционных осложнений мы не наблюдали.

Сравнение сроков стационарного лечения в исследуемых группах показывает отсутствие значимых различий в показателях длительности пребывания раненых в стационаре при значительном различии в тяжести местного повреждения. На наш взгляд это свидетельствует об эффективности прогрессивных хирургических технологий, таких как вакуумная терапия и васкуляризированная кожная пластика, в лечении раненых с огнестрельными дефектами мягких тканей конечностей. Вместе с тем следует отметить, что более широкое применение вакуумной терапии, вероятно, могло бы существенно сократить сроки лечения раненых с глубокими кожными дефектами (раненые 1-й группы) при наличии должного материальнотехнического обеспечения.

\section{В Ы В О д Ы}

- применение кожно-пластических вмешательств является обязательным компонентом хирургического лечения огнестрельных ранений нижней конечности, сопровождающихся дефектом покровных тканей;

- выбор метода кожно-пластического закрытия дефекта при огнестрельных ранениях конечности должен носить индивидуализированный и дифференцированный характер, основанный на многофакторной оценке раневого дефекта, тяжести ранения и состояния раненого;

- применение вакуумной терапии ран является важным этапом подготовки их к пластическому закрытию;

- лоскуты с осевым типом кровоснабжения являются приоритетным вариантом закрытия глубоких дефектов тканей в области крупных суставов и дистальных отделов нижней конечности;

- пластическое замещение глубоких дефектов мягких тканей лоскутами с осевым типом кровоснабжения при открытых боевых повреж- 
дениях конечности представляется важным элементом предупреждения и лечения гнойнонекротических осложнений;

- пластика местными лоскутами с осевым кровотоком характеризуется относитель- ной простотой, малой травматичностью, минимальными требованиями к материальнотехническому обеспечению и может представлять альтернативу свободной микрососудистой трансплантации.

\section{А.А. Оприщенко ${ }^{1}$, А.А. Штутин ${ }^{1}$, И.В. Коктышев}

${ }^{1}$ Республиканский травматологический центр, Донецк ${ }^{2}$ ГОО ВПО «Донецикий национальный медицинский университет имени М. Горького», Донецк

\section{ТАКТИКА ПЛАСТИЧЕСКОГО ЗАКРЫТИЯ ОГНЕСТРЕЛЬНЫХ РАНЕВЫХ ДЕФЕКТОВ НИЖНЕЙ КОНЕЧНОСТИ}

Цель исследования: анализ эффективности различных вариантов пластического закрытия огнестрельных дефектов нижних конечностей в условиях локального военного конфликта.

Материал и методы исследования. Проведен ретроспективный анализ 119 клинических наблюдений раненых с открытыми боевыми повреждениями нижних конечностей, сопровождающихся глубокими и обширными дефектами мягких тканей. Мужчин было 106 (89,1\%), женщин - 13 (10,9\%). Средний возраст $34,3 \pm 2,9$ года (от 21 до 51). Пулевые ранения имели место у $28(23,5 \%)$, взрывная травма - 91 (76,5\%), в том числе минно-взрывные повреждения 43 (36,1\%) раненых. Переломы IIIB типа (по классификации Gustilo-Andersen) имели место у 76 (63,9\%) раненых, разрушения конечности, повлекшие первичную ампутацию - 43 (36,1\%). Травматический шок 2-3 степени установлен у 27 (22,7\%) раненых. Площадь раневых дефектов составила в среднем $107 \pm 12 \mathrm{~cm}^{2}$ $(79,5-186,5)$. Раненые были разделены на три группы: 1 группа - 32 пациента с ранениями без обнажения кости и других важных анатомических образований, у которых использовали традиционные методы кожно-пластического закрытия ран; 2 группа - 56 раненых, которым применяли вакуумную терапию с последующей аутодермопластикой расщепленными или местными перемещенными лоскутами; 3 группа - 31 раненый, которым закрытие ран производили посредством комбинированной васкуляризированной (островковой) лоскутной пластики.

Результаты. В 1 группе средний срок закрытия ран составил 29,5 $\pm 5,4$ суток $(18,4-38,6)$. Частичный лизис аутодермотрансплантатов имел место в 7 случаях, в 3 из которых потребовались повторные вмешательства. Во всех случаях ближайший результат лечения был оценен как удовлетворительный. Средний срок пребывания на койке составил $38,5 \pm 7,2$ суток. Во 2 группе окончательное закрытие ран произведено аутодермопластическим методом в 43 наблюдениях, в 13 случаях - путем перемещения кожных лоскутов. Средний срок стационарного лечения составил $36,5 \pm 7,4$ суток. Локальных и генерализованных инфекционных осложнений не наблюдали. В 3 группе средний срок стационарного составил $46 \pm 9,8$ суток (39,5-76,8). Инфекционных осложнений не наблюдали. В 4 наблюдениях имел место краевой некроз лоскутов, не повлиявший на окончательный результат.

Заключение. Дифференцированное применение кожно-пластических вмешательств является обязательным компонентом хирургического лечения огнестрельных ранений нижней конечности и представляется важным элементом предупреждения и лечения гнойно-некротических осложнений.

Ключевые слова: боевые повреждения нижней конечности, раневые дефекты, лечение, пластическое закрытие, лоскуты.

\section{A.A. Oprishchenko ${ }^{1}$, A.A. Shtutin ${ }^{1}$, I.V. Koktyshev ${ }^{2}$}

${ }^{1}$ Republican Trauma Center, Donetsk

${ }^{2}$ SEI HPE «M. Gorky Donetsk National Medical University», Donetsk

\section{TACTICS OF PLASTIC CLOSURE OF GUNSHOT DEFECTS OF THE LOWER EXTREMITY}

Objective: analysis of the effectiveness of various options for plastic closure of gunshot defects of the lower extremities in a local military conflict.

Material and methods. A retrospective analysis of 119 clinical observations of the wounded with open lower limb injuries, accompanied by deep and extensive soft tissue defects, was carried out. Men were 106 (89.1\%), women 13 (10.9\%). The average age is $34.3 \pm 2.9$ years (from 21 to $51)$. Bullet injuries occurred in 28 (23.5\%), blast injuries 91 (76.5\%), including mine explosive injuries - 43 (36.1\%). Fractures of type III occurred in 76 (63.9\%) wounded, primary amputation - 43 (36.1\%). A traumatic shock of $2-3$ degrees was established in 27 (22.7\%). The area of wound defects averaged $107.1 \pm 12.0 \mathrm{~cm} 2$ [79.5 - 186.5]. The wounded were divided into three groups: 1 group - 32 patients with wounds without exposing the bone and other important anatomical structures, which used traditional methods of skin-plastic wound closure; Group $2-56$ wounded who were given vacuum therapy followed by autodermoplasty by split grafts or local flaps; Group 3- 31 treated by combined vascular (island) plastics.

Results. In group 1 the average wound closure time was $29.5 \pm 5.4$ days [18.4 - 38.6]. Partial lysis of grafts occurred in 7 cases, 3 of which required repeated interventions. In all cases, the immediate outcome of the treatment was assessed as satisfactory. The average length of 
staying in bed was $38.5 \pm 7.2$ days. In group 2 , the final wound closure was performed by the autodermoplasty in 43 cases, in 13 cases by random skin flaps. The average duration of inpatient treatment was $36.5 \pm 7.4$ days. Local and generalized infectious complications were not observed. In group 3 , the average stationary period was 46 \pm 9.8 days [39.5 - 76.8]. No infectious complications were observed. In 4 cases there was marginal necrosis of the flaps, which did not affect the final result.
Conclusion. Differentiated use of skin plastic interventions is an essential component of the surgical treatment of gunshot wounds of the lower limb and is an important element in the prevention and treatment of purulent-necrotic complications.

Key words: combat injuries of the lower limb, wound defects, treatment, plastic closure, flaps.

\section{ЛИТЕРАТУРА}

1. Гуманенко Е.К., Самохвалов И.М. Военно-полевая хирургия локальных войн и вооруженных конфликтов: Руководство для врачей. М.: ГЭОТАР-Медиа; 2011. 672.

2. Belmont P.J., Owens B.D., Schoenfeld A.J. Musculoskeletal Injuries in Iraq and Afghanistan: Epidemiology and Outcomes Following a Decade of War. J Am Acad Orthop Surg. 2016; 24 (6): 341-348. doi:10.5435/JAAOS-D-15-00123

3. Dougherty P.J, Najibi S., Silverton C., Vaidya R. Gunshot wounds: epidemiology, wound ballistics, and soft-tissue treatment. Instr. Course Lect. 2009; 58: 131-139.

4. Bartlett C.S., Helfet D.L., Hausman M.R., Strauss E. Ballistics and gunshot wounds: effects on musculoskeletal tissues. I Am Acad Orthop Surg. 2000; 8 (1): 21-36.

5. Rhee P.M., Moore E.E., Joseph B., Tang A., Pandit V., Vercruysse G. Gunshot wounds: A review of ballistics, bullets, weapons, and myths. J Trauma Acute Care Surg. 2016; 80 (6): 853-867. doi:10.1097/ PMID: 26982703

6. Manring M.M., Hawk A., Calhoun J.H., Andersen R.C. Treatment of war wounds: a historical review. Clinical orthopaedics and related research. 2009; 467 (8): 2168-2191.

7. Connolly M. [et al.] Changing paradigms in lower extremity reconstruction in war-related injuries. Military Medical Research. 2016; 3: 9.

8. Липинский П.В. Лечение пациентов с открытыми переломами длинных костей конечностей, сопровождающимися обширным повреждением мягких тканей: автореф. дис. канд. мед.наук. Москва; 2012. 24.

9. Тихилов Р.М., Кочиш А.Ю., Родоманова Л.А. [и др.] Возможности современных методов реконструктивнопластической хирургии в лечении больных с обширными посттравматическими дефектами тканей конечностей. Травматология и ортопедия России. 2011; 2 (60): 164-170.

10. Gustilo R.B., Mendoza R.M., Williams D.N. Problems in management of type III (severe) open fractures: a new classification of type III open fractures. J Trauma. 1984; 24: 742-746. doi: 10.1097/00005373-198408000-00009

11. Гуманенко Е.К., Бояринцев В.В., Супрун Т.Ю., Ляшедько П.П. Объективная оценка тяжести травм. СПб.: Воен.-мед.акад.; 1999. 110.

12. Ruedi N.P., Buckley R.E., Moran C.G. AO principles of fracture management. Stuttgart: Thieme; 2007. 1106.

\section{REFERENCES}

1. Gumanenko E.K., Samokhvalov I.M. Voenno-polevaya khirurgiya lokal'nykh voin i vooruzhennykh konfliktov: Rukovodstvo dlya vrachei. M.: GEOTAR-Media; 2011. 672 (in Russian).

2. Belmont P.J., Owens B.D., Schoenfeld A.J. Musculoskeletal Injuries in Iraq and Afghanistan: Epidemiology and Outcomes Following a Decade of War. J Am Acad Orthop Surg. 2016; 24 (6): 341-348. doi:10.5435/JAAOS-D-15-00123

3. Dougherty P.J, Najibi S., Silverton C., Vaidya R. Gunshot wounds: epidemiology, wound ballistics, and soft-tissue treatment. Instr. Course Lect. 2009; 58: 131-139.

4. Bartlett C.S., Helfet D.L., Hausman M.R., Strauss E. Ballistics and gunshot wounds: effects on musculoskeletal tissues. J Am Acad Orthop Surg. 2000; 8 (1): 21-36.

5. Rhee P.M., Moore E.E., Joseph B., Tang A., Pandit V., Vercruysse G. Gunshot wounds: A review of ballistics, bullets, weapons, and myths. J Trauma Acute Care Surg. 2016; 80 (6): 853-867. doi:10.1097/ PMID: 26982703

6. Manring M.M., Hawk A., Calhoun J.H., Andersen R.C. Treatment of war wounds: a historical review. Clinical orthopaedics and related research. 2009; 467 (8): 2168-2191.

7. Connolly M. [et al.] Changing paradigms in lower extremity reconstruction in war-related injuries. Military Medical Research. 2016; 3: 9.

8. Lipinskii P.V. Lechenie patsientov s otkrytymi perelomami dlinnykh kostei konechnostei, soprovozhdayushchimisya obshirnym povrezhdeniem myagkikh tkanei: avtoref. dis. kand. med.nauk. Moskva; 2012. 24 (in Russian).

9. Tikhilov R.M., Kochish A.Yu., Rodomanova L.A. [i dr.] Vozmozhnosti sovremennykh metodov rekonstruktivno-plasticheskoi khirurgii v lechenii bol'nykh s obshirnymi posttravmaticheskimi defektami tkanei konechnostei. Travmatologiya i ortopediya Rossii. 2011; 2 (60): 164-170 (in Russian).

10. Gustilo R.B., Mendoza R.M., Williams D.N. Problems in management of type III (severe) open fractures: a new classification of type III open fractures. J Trauma. 1984; 24: 742-746. doi: 10.1097/00005373-198408000-00009

11. Gumanenko E.K., Boyarintsev V.V., Suprun T.Yu., Lyashed'ko P.P. Ob"ektivnaya otsenka tyazhesti travm. SPb.: Voen.-med.akad.; 1999. 110 (in Russian).

12. Ruedi N.P., Buckley R.E., Moran C.G. AO principles of fracture management. Stuttgart: Thieme; 2007. 1106. 